\title{
Balkanologie
}

Balkanologie Revue d'études pluridisciplinaires

Vol. VI, $n^{\circ}$ 1-2 | 2002

Volume VI Numéro 1-2

\section{Le monastère de Saint-Naum (Sveti Naum/Shën}

Naum)

The Sveti Naum monastery

Bernard Lory et Petrit Nathanaili

\section{(2) OpenEdition}

12 Journals

Édition électronique

URL : http://journals.openedition.org/balkanologie/431

DOI : 10.4000/balkanologie.431

ISSN : 1965-0582

Éditeur

Association française d'études sur les Balkans (Afebalk)

Édition imprimée

Date de publication : 1 décembre 2002

Pagination : 35-40

ISSN : 1279-7952

\section{Référence électronique}

Bernard Lory et Petrit Nathanaili, « Le monastère de Saint-Naum (Sveti Naum/Shën Naum) », Balkanologie [En ligne], Vol. VI, n 1-2 | 2002, mis en ligne le 03 février 2009, consulté le 17 décembre 2020. URL : http://journals.openedition.org/balkanologie/431 ; DOI : https://doi.org/10.4000/ balkanologie. 431

(c) Tous droits réservés 


\title{
LE MONASTÈRE DE SAINT-NAUM [SVETI NAUM/SHËN NAUM]
}

\author{
Bernard Lory*et Petrit Nathanaili**
}

Il est des endroits que la nature marque d'un cachet d'exception et, quelle que soit leur langue ou leur religion, les hommes y sont sensibles. Maurice Barrès parlait de " lieux où souffle l'Esprit ". Serti dans les âpres reliefs albanomacédoniens, le lac d'Ohrid offre sa surface lisse et limpide comme une caresse aux regards et un climat d'une douceur exceptionnelle pour la région. Sur son rivage sud-est, une source de résurgence importante est connue pour être celle du Drin. Juste à l'endroit où ses eaux claires se déversent dans le lac, un rocher se dresse en promontoire. Ce rocher a fait l'objet d'un contentieux territorial entre Serbes et Albanais de 1913 à 1925.

Mais les charmes naturels du site sont loin de tout expliquer : des enjeux historiques, religieux et d'idéologie nationale s'y imbriquent étroitement. $\mathrm{Ce}$ rocher en éperon sur le lac fut en effet choisi au tournant du IX ${ }^{\mathrm{e}}$ et du $\mathrm{X}^{\mathrm{e}}$ siècle par saint Naum pour y établir un monastère. Moins connu que saints Cyrille et Méthode, dont il fut le disciple, il partage leur culte sous l'invocation collective des Sept Apôtres des Slaves (Sveti Sedmočislenici). A cette époque, le peuplement slave s'étendait, semble-t-il, profondément à l'ouest, dans les vallées du Devoll et du Shkumbin, où il laissa des traces dans la toponymie. La figure de saint Naum, telle que nous la présentent l'hagiographie médiévale et la tradition populaire, est davantage celle d'un ermite évangélisateur que celle d'un promoteur des lettres et de la machine hiérarchique, comme saint Clément d'Ohrid, son confrère. Ses reliques, qui depuis sa mort en 910 n'ont pas quitté le monastère, sont également vénérées par les Slaves et les Albanais orthodoxes

\footnotetext{
- Maître de conférences à l'INALCO.

* Professeur associè en histoire contemporaine et relations internationales, département d'histoire, Université de Tirana.
} 
de la région. Dans les deux groupes, le prénom de Naum jouit de la même popularité.

Le culte du saint est plus large encore. Un expert international le signale : Par la conviction que ce saint temple est la vraie maison du Dieu universel et tout puissant, indépendante des religions et des sectes, et aussi par respect des traditions héritées, toutes les populations chrétiennes et musulmanes des districts voisins de Starova, Korça, Bilisht et même Elbasan vont chaque année, le 3 juillet, visiter ce monastère et y laissent des dons souvent considérables. L'entretien du monastère est assuré toujours par les dons de cette population ${ }^{1}$.

Saint Naum a en effet été identifié par les musulmans à Sarı Saltık, prédicateur et thaumaturge revendiqué par la mouvance bektachie, dont le moindre miracle ne fut pas d'annoncer qu'après sa mort son corps se multiplierait, si bien qu'il a - au moins - sept tombeaux authentiques (par exemple à Babadag en Dobrogea roumaine). La tombe de saint Naum fait donc l'objet d'un culte utraquiste, comme celle de saint Dimitri/Kasım à Salonique. Le saint est particulièrement invoqué pour les troubles mentaux (étymologie populaire : na um, “à l'esprit"). Les âmes pures peuvent, dit-on, entendre le cœur du saint battre sous sa pierre tombale.

Le monastère connut les vicissitudes de l'histoire. L'église actuelle, de fort petites dimensions, date du XVI ${ }^{\mathrm{e}}$ siècle, ses fresques de 1806 , les bâtiments conventuels sont récents. La fête du saint, le 23 décembre st. st. était l'occasion d'une foire à laquelle affluait la population de toute la région sans distinction de langue ni de religion. En 1727, il fut décidé de déplacer ce grand rassemblement à une saison plus propice, soit le 20 juin ( 3 juillet selon le calendrier grégorien). Au XVIII ${ }^{\mathrm{e}}$ siècle, le couvent reçut des subsides des hospodars de Valachie. Au milieu du XIX ${ }^{\mathrm{e}}$ siècle il connaissait de sérieuses difficultés financières.

C'est vers cette époque aussi qu'il devient un enjeu idéologique. Le mouvement d'affirmation nationale des Slaves de Bulgarie et de Macédoine passe par le rejet de la liturgie en langue grecque et la revalorisation de la liturgie slavonne. Le culte de saints Cyrille et Méthode, et, de manière connexe, de leurs disciples immédiats, acquiert une popularité nouvelle dans une approche nationaliste. Ce mouvement touche la région d'Ohrid à partir des années 1860. En 1874, l'éparchie d'Ohrid est une des premières de Macédoine à obtenir son rattachement à l'Exarchat bulgare. Il est à noter cependant que la communauté monastique de Saint-Naum reste fidèle au patriarcat de Constantinople :

Pour le service rituel, les Igoumènes - chefs religieux - étaient le plus souvent directement choisis par le Patriarcat; si, quelques fois, l'évêque d'Ohrida était chargé de leur

\footnotetext{
${ }^{1}$ AMAE, Correspondance politique et commerciale 1914-1940, Société des Nations : Frontière albanaise dans la région de Saint-Naoum : Note sur les délibérations de la Conférence des ambassadeurs au sujet de l'attribution du monastère de St-Naoum, C. 293, M.94.1924. VII .pp. 18-19.
} 
nomination, il les choisissait invariablement parmi les prélats orthodoxes albanais. Le gouvernement ottoman ne se préoccupait pas directement de ces questions d'ordre religieux qu'il considérait d'une portée locale. Aussi en reliant le monastère de St Naoum à l'évéché d'Ohrida, au lieu de celui de Kortça, il subissait sûrement l'influence des menées sournoises de quelques personnes intéressées. Du reste, Ohrida lui appartenait aussi bien que Kortça. Tout de même, pour satisfaire les fervents sentiments de piété des populations voisines et surtout considérant que les Exarchistes n'avaient aucun droit, il avait favorisé le maintien du rattachement du monastère au Patriarcat ${ }^{2}$.

Une des raisons de l'attachement du monastère au Patriarcat est sans doute la modification des rapports ethniques dans la région. Le peuplement albanais prédomine désormais largement dans la région de Korça ; un slavisme résiduel se maintient encore à Boboshtica et Drenova. Cette position en bordure des deux grands ensembles linguistiques slave et albanais n'avait jamais posé de problème au monastère de Saint-Naum, jusqu'à ce qu'en 1913 on ne s'avise de déterminer sur le terrain les limites d'un Etat albanais.

La Première Guerre balkanique éclata en octobre 1912 et, dès les premiers succès de la coalition balkanique, les Grandes Puissances s'efforcèrent d'infléchir sur le plan diplomatique le cours d'événements militaires sur lesquels elles n'avaient pas prise. L'Autriche-Hongrie surtout s'engagea en faveur de la création de l'Etat albanais et en fit admettre le principe à la séance du 17 décembre 1912 par la Conférence des Ambassadeurs réunie à Londres. La question de l'étendue géographique du nouvel Etat fut longuement débattue et différents projets de frontières furent proposés. Les deux puissances les plus nettement engagées en faveur de la cause albanaise, l'Autriche-Hongrie et l'Italie, proposèrent le 19 mars 1913 un tracé partant " de la rive méridionale du lac d'Ohrid entre le couvent de Saint-Naoum, qui resterait hors de l'Albanie et le bourg de Starova " et cette proposition fut réitérée le 21 mai. Le traité de Londres du 30 mai 1913 réservait aux Puissances, dans son article 3, "le soin de régler les frontières de l'Albanie et toutes autres questions concernant l'Albanie ". Les événements s'étant précipités sur le terrain avec la Deuxième Guerre balkanique, la décision finale des ambassadeurs n'intervint que le

\footnotetext{
${ }^{2}$ Ibid., p. 19. Les patriarchistes prétendirent que le monastère de Saint-Naum était une stauropégie, c'est à dire un monastère dépendant directement du Patriarcat de Constantinople, comme ceux du Mont Athos. Il dépendait en fait de l'évêque d'Ohrid, mais dans de nombreux évêchés, depuis le schisme de 1872 , on avait deux hiérarchies rivales qui cohabitaient vaille que vaille. Le pouvoir ottoman ne reconnaissait comme partenaire officiel (comme millet bașı) que l'évêque auquel il avait décerné un berat. L'évêchẻ d'Ohrid fut attribué aux exarchistes en 1874, puis connut une période de vacance entre 1877 et 1890 , avant d'obtenir à nouveau un berat. Parallèlement, un évêque patriarchiste, n'ayant pas reçu de berat de la Sublime Porte exerçait son autorité sur une minorité de fidèles. Il résidait en génèral à Kruševo. C'est de cet évêque "officieux" que dépendait le monastère de St-Naum. L'higoumène de StNaum fut longtemps, jusqu'après les guerres balkaniques, l’Albanais Stefan Gjergji.
} 
11 août 1913. Elle allait un peu au-delà des propositions austro-italiennes en stipulant : "Il est dès à présent établi que (...) l'ancien kaza ottoman de Koritza avec la rive ouest et sud du lac d'Ohrid s'étendant du village de Lin jusqu'au monastère de Sveti Naoum font intégralement partie de l'Albanie ".

Une commission internationale de délimitation de la frontière œuvra sur le terrain d'octobre à décembre 1913, mais principalement préoccupée de séparer Grecs et Albanais, elle ne "traita" pas le secteur du lac d'Ohrid ; ce ne fut pas davantage fait au printemps de 1914, si bien que, lorsqu'éclata la Première Guerre mondiale, le bornage n'était pas encore réalisé. Concrètement, le monastère de Saint-Naum était dans la zone d'occupation militaire serbe. Il y resta jusqu'à la fin de 1915, puis les Bulgares l'occupèrent, jusqu'au retour des Serbes en 1917 (retour théorique, car ce secteur du front était tenu par des soldats français).

Créé le $1^{\mathrm{er}}$ décembre 1918 , le Royaume des Serbes, Croates et Slovènes eut à résoudre un grand nombre de problèmes frontaliers, en particulier avec l'Italie, l'Autriche et la Hongrie. Le monastère de Saint-Naum ne représentait qu'un enjeu dérisoire dans un contexte où se décidait du sort de provinces riches et populeuses. Lorsque la Conférence de la Paix se réunit à Paris, en 1919, elle se considéra comme compétente pour s'occuper, entre autres, de la question albanaise. A partir de 1920, l'Albanie entra en relation avec la Société des Nations, à laquelle elle demanda son admission. Droit fut fait à cette demande par une décision de l'Assemblée de la SDN, le 17 décembre 1920. La Résolution réservait expressément la question de la délimitation des frontières du nouveau membre.

Une fois admise à la SDN, l'Albanie saisit le Conseil de la question de l'évacuation de son territoire (tel qu'il avait été défini par la Conférence de Londres en 1913) par les troupes serbes et grecques qui y stationnaient. Elle aurait souhaité que la SDN se saisisse de la question de la délimitation des frontières. Cependant, par son vote unanime du 2 octobre 1921, l'Assemblée de la SDN estima que la tâche incombait aux Principales Puissances alliées (ce qu'avaient réclamé la Yougoslavie et la Grèce), et recommandait d'ores et déjà à l'Albanie de se soumettre à leur décision.

La Conférence des Ambassadeurs, comprenant la Grande-Bretagne, la France, l'Italie et le Japon, décida le 9 décembre 1921 de régler la question des frontières de l'Albanie. Cependant, une Commission d'enquête, envoyée par la SDN en Albanie, signala des difficultés, entre autres dans le secteur du monastère de Saint-Naum. Plus tard, en août 1922, au sein de la Commission de délimitation sur le terrain, un doute s'éleva parmi les commissaires sur l'interprétation à donner aux termes du Protocole de Londres jusqu'au monastère de Saint Naoum. L'intention de ses rédacteurs avait-elle été d'attribuer le monastère à la Serbie ou à l'Albanie ? L'enjeu était de nature symbolique, car le monastère ne comptait à l'époque que deux moines, l'un de langue albanaise, 
l'autre de langue serbe, qui y avaient d'ailleurs été envoyés, l'un et l'autre, par les autorités yougoslaves.

Le gouvernement britannique saisit la Conférence des Ambassadeurs de cette difficulté3. Les membres de la Commission de délimitation transmirent à cette dernière leurs avis motivés4. Des arguments ethniques, géographiques et stratégiques étaient avancés. On ergota sur la signification de la préposition "jusque", on fit des recherches sur la délimitation exacte des kazas ottomans de Korça et d'Ohrid, on inventa même une protection des souverains serbes médiévaux sur le monastère. Il était difficile de déterminer les intentions des auteurs du Protocole de Londres de 1913, car ils n'avaient pas laissé de procèsverbaux réguliers, ni de carte officielle indiquant le tracé qu'ils avaient retenu. D'après les renseignements recueillis sur place, l'avis du commissaire français était que :

les Albanais contribuèrent depuis très longtemps à l'entretien de ce monastère, qui possède des propriétés en Albanie, en particulier à Pendavin près de Koritza. Toute la région avoisinante, selon ces informations, appartient depuis des siècles à des Albanais et les villages de Tushemiste, Zagoriçan, Cerava, Platza et Halarup sont habités par des Albanais5.

Dans ces conditions, la Conférence des Ambassadeurs dut trancher. Considérant surtout les arguments ethniques et économiques produits par les membres de la Commission de délimitation, elle se prononça pour le rattachement du monastère de Saint-Naum à l'Albanie le 6 décembre 1922.

Le gouvernement yougoslave ne réagit pas et ne protesta que quatre mois plus tard, le 27 mars 1923, car il traversait une de ses fréquentes crises intérieures. Appuyé par le représentant français à la Conférence des Ambassadeurs, il réclama une révision de la décision du 6 décembre $^{6}$. La querelle fut portée d'instance en instance jusqu'à la Cour de Justice de La Haye, qui donna raison aux Albanais, le 4 septembre $1924^{7}$.

Le 24 décembre de la même année, Ahmed Zogu renversait le gouvernement de Fan Noli, non sans l'aide de Belgrade. Il fit promptement remanier la constitution et ouvrit des négociations avec le représentant yougoslave à Tirana, Cincar-Marković dès le 8 février 1925. Après divers atermoiements, un arrangement de rectification de frontières dû à la proposition de la Conférence des Ambassadeurs, fut trouvé le 5 août 1925, laissant définitivement le monas-

${ }^{3}$ AMAE, SDN, Note du 27 septembre 1922, pp. 10-11.

4 AMAE, SDN, Lettre du 5 novembre 1922, p. 11

5 Ibid. , p.16

${ }^{6}$ AMAE, SDN, Note du 6 avril 1923, pp. 22-23.

7 AMAE, Corresp. Pol. Com. 1914-1940; Publications de la Cour Permanente de Justice Internationale, Série $\mathrm{B}-\mathrm{N}^{\circ} 9$, Affaire du monastère de Saint Naoum. 
tère de Saint-Naum du côté yougoslave. Cette proposition fut approuvée par le Parlement albanais le 14 octobre 1925. L'accord fut présenté par Zogu, non comme un acte de cession, mais comme un échange territorial avec le gouvernement yougoslave. Le protocole final de délimitation de la frontière yougoslavo-albanaise fut signé le 26 juillet 1926 à Florence.

Désormais yougoslave, le monastère fut promu résidence royale, mais il ne semble pas que les Karadjordjević en aient beaucoup profité (la reine Marie affectionnait Miločer sur le littoral monténégrin). Ils firent néanmoins construire un grand donjon blanc (un pirgos dans le style athonite) qui écrasait de sa masse la petite église avec le tombeau du saint. Il s'agissait d'inscrire dans le paysage, de façon péremptoire, la limite entre Slaves et Albanais. Ce pirgos, jugé trop agressivement serbe (la croix cantonnée de quatre briquets était inscrite dans la maçonnerie), fut démoli en 1958 par les autorités de Skopje.

Le monastère de Sveti Naum reste aujourd'hui un lieu très fréquenté, tant par les fidèles que par les touristes. L'ouverture d'un poste-frontière entre la Macédoine et l'Albanie a contribué à désenclaver la région.

\section{SOURCES UTILISÉES :}

Akademia e Shkencave e RPSSH, Instituti i Historisë, Çështje të lëvizjes demokratike dhe revolucionare shqiptare në vitet 1921-1924 (Les questions du mouvement démocratique et révolutionnaire albanais dans les années 1921-1924), Tirana, 1977, pp. 173-199.

Archives du Ministère des Affaires Etrangères (AMAE) Correspondance Politique et Commerciale 19141940, Délimitation des frontières de l'Albanie (1921-1926), vol. 66-75.

Balevski (Milčo), Balkanskite politički priliki i diplomatskite bitki za manastirot Sveti Naum (Les circonstances politiques balkaniques et les luttes diplomatiques pour le monastère de Sveti Naum), Skopje, 1974, 267 p. (bibliographie).

Hasluck (F.W), Christianity and Islam under the Sultans, Oxford, 1929.

Institut za nacionalna istorija, Ohrid I Ohridsko niz istorijata (Ohrid et sa région au cours de l'histoire), Skopje, 1978, t. 2, pp. 163-177.

Puto (Arben), La question albanaise dans les actes internationaux de l'époque impérialiste, Tirana 1988, 403 et $696 \mathrm{p}$.

Çështja shqiptare në aktet ndërkombëtare pas Luftës së Parë Botërore (La question albanaise dans les actes internationaux après la Première Guerre mondiale), Tirana, 2001, pp. 361-383.

Simonard (André), Essai sur l'indépendance albanaise, Paris, 1942.

Snegarov (Ivan), Monastirăt Sveti Naum pri Ohridskoto Ezero, Sofia, 1972, 70 p. 